\title{
Resistance to Puccinia graminis f. sp. avenae in Barley Is Associated with the Rpg5 Locus
}

\author{
Peter Dracatos, Davinder Singh, Tom Fetch Jr., and Robert Park
}

First, second, and fourth authors: The University of Sydney, Plant Breeding Institute Cobbitty, Private Bag 4011, Narellan, NSW, 2567, Australia; and third author: Cereal Research Centre, Agriculture \& Agri-Food Canada, Winnipeg, MB, Canada. Accepted for publication 17 December 2014.

\begin{abstract}
Dracatos, P., Singh, D., Fetch, T., Jr., and Park, R. 2015. Resistance to Puccinia graminis f. sp. avenae in barley is associated with the Rpg5 locus. Phytopathology 105:490-494.

In barley, gene Rpg5 was first identified for providing resistance to the rye stem rust pathogen (Puccinia graminis $\mathrm{f}$. sp. secalis). A subsequent study determined that Rpg5 is required for rpg4-mediated resistance to the wheat stem rust pathogen $(P$. graminis $\mathrm{f}$. sp. tritici) including pathotype TTKSK ("Ug99"), which poses a major threat to global wheat and barley production. Based on the effectiveness of Rpg5 against $P$. graminis f. sp. tritici and $P$. graminis f. sp. secalis, we assessed whether it also conferred resistance to the oat stem rust pathogen ( $P$. graminis f. sp. avenae). A barley $\mathrm{F}_{8}$ recombinant inbred line (RIL) population was produced by crossing 'Q21861' (Rpg1 and Rpg5) with '73-G1' (Rpgl), which is susceptible to $P$. graminis f. sp. avenae, $P$. graminis f. sp. secalis,

and some pathotypes of $P$. graminis f. sp. tritici. Seedling tests were performed on the $\mathrm{F}_{8}$ RIL population using Australian pathotypes of $P$. graminis f. sp. tritici, $P$. graminis $\mathrm{f}$. sp. secalis, $P$. graminis f. sp. avenae, and a putative somatic hybrid between $P$. graminis f. sp. tritici and $P$. graminis f. sp. secalis known as the 'Scabrum' rust. Segregation in the responses to all rust isolates for the RILs was identical (50 resistant: 52 susceptible), and fitted a $1: 1$ ratio $\left(\mathrm{X}^{2}=0.039, P=0.843\right)$, indicating that resistance to all isolates was monogenetically inherited. Screening of the RILs and the parental lines with perfect markers for the functional Rpg1 and Rpg5 resistance alleles indicated that Rpgl was fixed, while Rpg5 was positive in all resistant lines and negative in all susceptible lines. This suggests that different formae speciales of $P$. graminis may share common effectors, and that the Rpg5 locus confers resistance to both $P$. graminis f. sp. tritici and $P$. graminis $\mathrm{f}$. $\mathrm{sp}$. secalis and the heterologous formae speciales of $P$. graminis, $P$. graminis $f$. sp. avenae.
\end{abstract}

Stem rust, caused by Puccinia graminis, is a major disease of cereals and grasses worldwide, and can cause complete crop failure when severe $(8,25,33)$. The species $P$. graminis is divided into both subspecies and formae speciales, based primarily on urediniospore morphology and host range, respectively. Currently, several formae speciales of $P$. graminis are recognized including tritici, secalis, avenae, agrostidis, poae, airae, and lolii $(1,17)$. The $P$. graminis f. sp. tritici form has a wider host range than other formae speciales (28 hosts from 8 genera) (1) and is most commonly found on wheat, but also infects barley and cereal rye, while $P$. graminis f. sp. secalis can infect rye and barley, but only very few wheat genotypes. The $P$. graminis f. sp. avenae form is not closely related to other formae speciales of $P$. graminis based on difficulty to cross hybridize (1), and it is specialized mainly to Avena spp. and other grasses within the Pooideae subtribe. This was further supported by DNA sequencing of the internal transcribed spacer regions of nuclear rDNA from different $P$. graminis formae speciales, which determined that $P$. graminis f. sp. tritici was very closely related to $P$. graminis $\mathrm{f}$. spp. dactylis, lolii, and poae relative to f. spp. tritici and secalis (34). Evidence for both cultivated and native host grass species playing a part in the evolution and somatic hybridization of $P$. graminis also exists $(12,19)$. A putative somatic hybrid between $P$. graminis $\mathrm{f}$. sp. tritici and $P$. graminis f. sp. secalis was collected from Elymus scaber in a previous study and is informally referred to as the 'Scabrum' rust ('Scabrum') (19,22).

Barley (Hordeum vulgare L.) is considered a host to the wheat stem rust pathogen ( $P$. graminis $\mathrm{f}$. sp. tritici), the rye stem rust pathogen (P. graminis f. sp. secalis), and 'Scabrum' rust. Severe

Corresponding author: P. Dracatos; E-mail address: peter.dracatos@sydney.edu.au

http://dx.doi.org/10.1094/PHYTO-08-14-0224-R

(C) 2015 The American Phytopathological Society epidemics of $P$. graminis $\mathrm{f}$. sp. tritici have occurred on barley in Australia, and the disease has posed a serious threat to barley production in the United States and Canada, especially prior to the deployment of the durable resistance gene Rpgl in 1942 (29). In barley, several resistance genes effective to $P$. graminis f. sp. tritici have been described including Rpgl ('Peatland', 'Chevron', and 'Kindred') (24,27), Rpg2 ('Heitpas 5') (23), Rpg3 ('PI 382313') (14,15), rpg4 ('Q21861') (16), and Rpg6 in the line '212Y1' that carries an introgression from $H$. bulbosum (10). Rpgl-mediated resistance proved durable based on the protection it has provided in North America for over 65 years; however, two pathotypes (QCCJ and TTKSK) of $P$. graminis f. sp. tritici were identified with virulence for Rpgl (28).

Three additional genes have been identified for resistance to $P$. graminis f. sp. secalis in barley. The partially dominant gene in 'Q21861' effective against North American pathotypes of $P$. graminis f. sp. secalis as originally designated as $R p g Q$, but more recently was designated as Rpg5 when high resolution mapping distinguished this gene from rpg4 $(5,6,30)$. Numerous studies involving high resolution genetic analysis and posttranscriptional silencing of candidate genes at the putative rpg4/Rpg5 locus on chromosome $5 \mathrm{HL}$ led to the hypothesis that four genes at two tightly linked loci were required in combination for resistance to $P$. graminis f. sp. tritici (32). Further examination of the alleles at the RMRL1 locus across both diverse domesticated and wild barley accessions determined that $H v R g a l$ did not contain polymorphisms that determine the compatible reactions, and that $H v A d f 3$ was identical at the amino acid level among all 22 accessions tested (2). This study demonstrated that these two candidates were expressed in both resistant and susceptible lines at the transcriptional level (2). Rpg5/rpg5 allele sequence analysis determined that single mutations accounted for amino acid substitutions or truncated proteins only found in barley accessions susceptible to Puccinia 
graminis f. sp. tritici. Taken together, it can be concluded that Rpg5 is a functional, polymorphic gene required for $r p g 4 / R p g 5$ resistance to $P$. graminis f. sp. tritici and $P$. graminis f. sp. secalis (2). The $R p g 5$ gene encodes a protein with a unique combination of three disease resistance motifs including a nucleotide binding siteleucine rich repeat (NBS-LRR) and serine threonine protein kinase (S/TPK) domain $(4,18)$. This along with current evidence for broad resistance specificity to two different formae speciales of $P$. graminis may suggest $R p g 5$ confers resistance to numerous formae speciales of $P$. graminis.

Previous studies have determined that some barley accessions showed moderate susceptibility to heterologous rust pathogen species and all known formae speciales of $P$. graminis including $P$. graminis $\mathrm{f}$. $\mathrm{sp}$. avenae $(3,9,20)$. Barley has been classified as a near nonhost to heterologous rust species and therefore is highly suitable for genetic analysis of resistance to different formae speciales within the $P$. graminis complex. An early study identified a Canadian barley selection ('73-G1') that was moderately susceptible to $P$. graminis including $P$. graminis $\mathrm{f}$. sp. avenae. In this study, we intercrossed '73-G1' with 'Q21861' to determine whether Rpg5 alone conferred resistance to multiple diverse P. graminis cultures. Diagnostic markers for both Rpg1 and Rpg5 were then screened on the recombinant inbred line (RIL) population to test for cosegregation of Rpg5 with resistant phenotypes in response to $P$. graminis. Given the unique gene structure of Rpg5 as an NBS-STK-LRR and the broad range of resistance to multiple North American pathotypes of $P$. graminis $\mathrm{f}$. sp. tritic $i$ and the closely related formae speciales $P$. graminis $\mathrm{f}$. $\mathrm{sp}$. secalis, we tested the hypothesis that Rpg 5 also confers resistance to Australian pathotypes of $P$. graminis f. sp. tritici, $P$. graminis f. sp. secalis, 'Scabrum', and the heterologous rust pathogen P. graminis f. sp. avenae.

\section{MATERIALS AND METHODS}

Plant materials. The parental barley lines used in this study were 'Q21861' (PI 584766; Rpg1, rpg4, Rpg5) and '73-G1' (Rpg1). In previous genetic studies the infection types (IT) produced at the seedling stage in barley line '73-G1' to Canadian pathotypes of $P$. graminis f. sp. avenae were consistently more compatible than those observed on other barleys. Although not fully susceptible, '73-G1' produced mesothetic reactions to $P$. graminis f. sp. avenae and was more resistant to $P$. graminis f. sp. tritici (intermediate IT) (20). An $\mathrm{F}_{8}$ RIL population was developed and 102 progeny were used for genetic analysis of resistance to $P$. graminis in this study. Wheat ('Morocco') and oat ('Swan') cultivars were used as positive control checks for inoculation in all experiments. Seedlings were grown in plastic pots ( $90 \mathrm{~mm}$ diameter) containing a potting mix comprising composted pine bark and coarse sand in a ratio of $4: 1$. Pots were fertilized with a soluble nitrogenous fertilizer (Aquasol, Hortico Pty Ltd., Australia) at the rate of $30 \mathrm{~g}$ in 10 liter of water for 200 pots prior to sowing. The RIL progeny were sown as clumps (four lines/pot) of approximately 10 seeds each. Postinoculation, the seedlings were fertilized with Aquasol: ammonium nitrate (1:1) at a rate of $25 \mathrm{~g}$ in 10 liter of water per 100 pots. Plants were maintained in a temperature-controlled greenhouse at $17^{\circ} \mathrm{C}$ prior to inoculation and $25^{\circ} \mathrm{C}$ after inoculation under natural lighting.

Inoculation procedures. Inoculations were performed on 10-day-old seedlings. Urediniospores $(150 \mathrm{mg}$ ) were suspended in approximately $5 \mathrm{ml}$ of light mineral oil (Isopar L) and sprayed with a mist atomizer over the top of the seedlings. The RIL population was phenotyped with three pathogenically diverse Australian P. graminis f. sp. tritici pathotypes (34-1,2,3,4,5,6,7; 343-1,2(3), (5),6,9; and 98-1,2,3,5,6,7), two $P$. graminis f. sp. avenae pathotypes $(41+P g 9, P g 13, P g A$; and $94+P g 13)$, and single isolates of

\section{A}

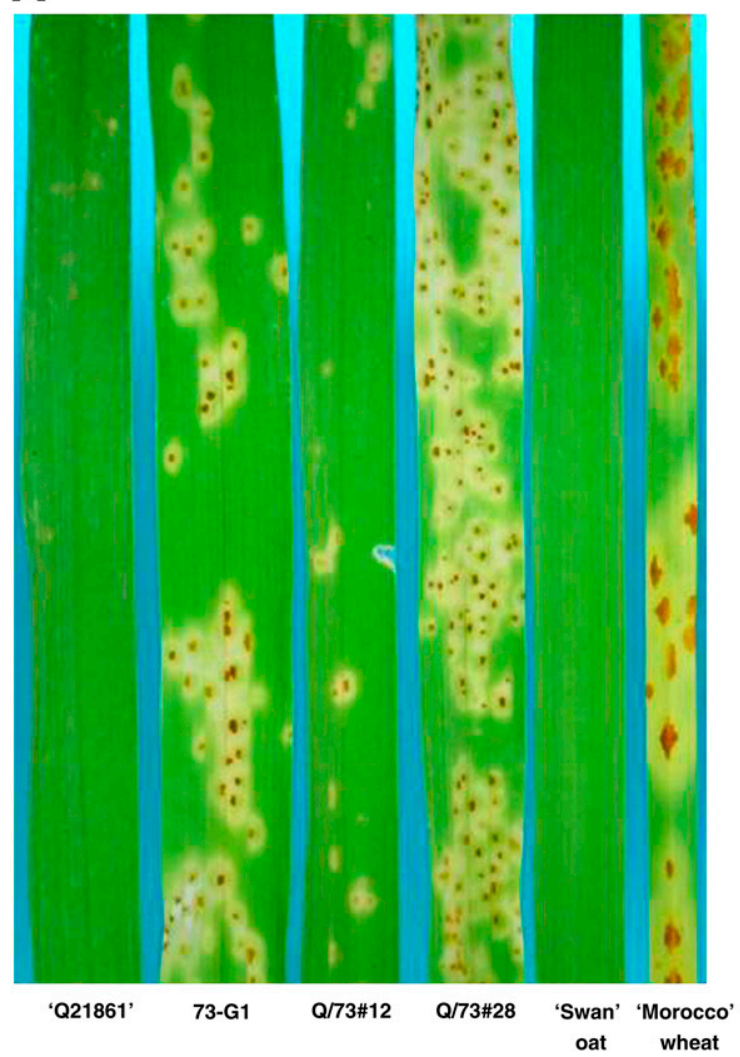

B

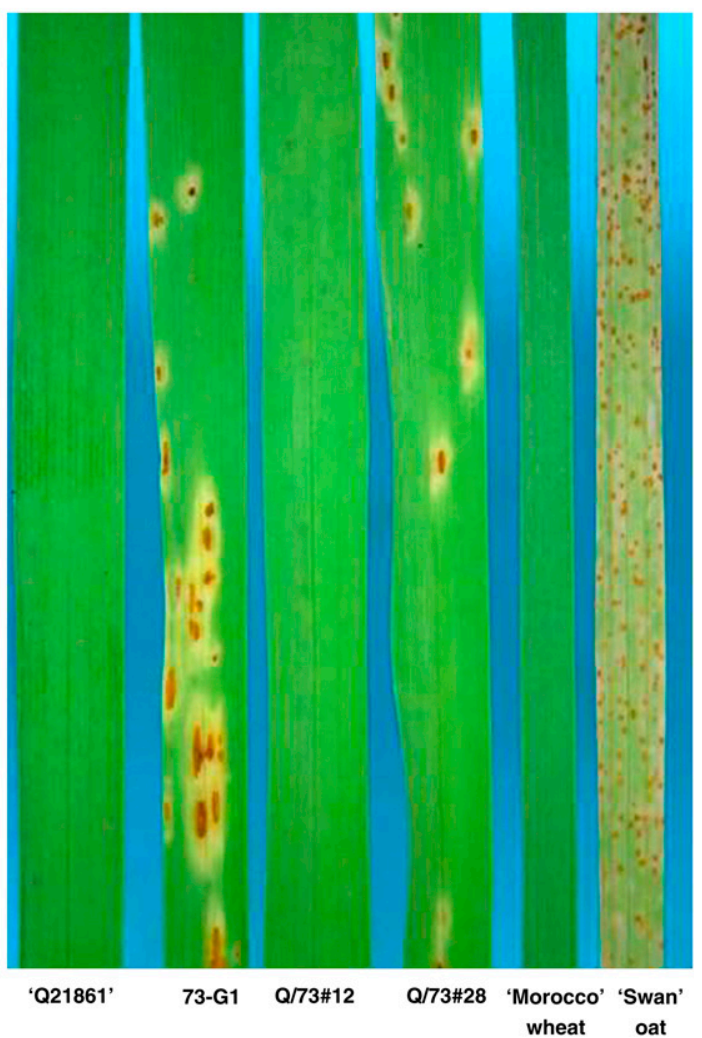

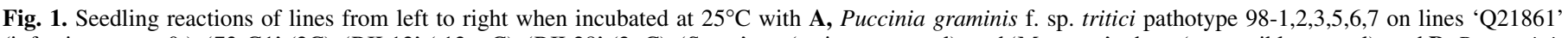

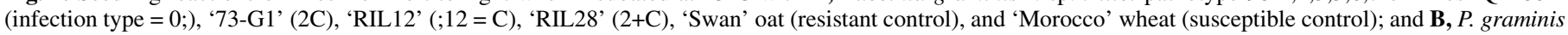

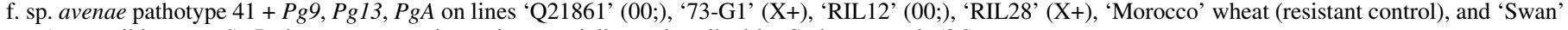
oat (susceptible control). Pathotype nomenclature is essentially as described by Stakman et al. (26). 
P. graminis f. sp. secalis (BWR '2') and 'Scabrum' ('Scabrum' + Sr21) (26) (Table 1). To prevent cross-contamination, the spray equipment was washed in $70 \%$ ethanol and rinsed in running tap water between successive inoculations. Seedlings inoculated with urediniospores were incubated for approximately $48 \mathrm{~h}$ over trays of water covered by sealed polythene hoods, under which sufficient dew (humidity) was generated. Incubation enabled the urediniospores to germinate and allowed rust infection to take place. After incubation, the plants were moved to greenhouse microclimate rooms for rust development.

Disease assessment. Disease response was assessed 12 days after inoculation using a modified 0 to 4 scale based on uredinial size (21). Variations of the ITs were indicated by the use of "-" (less than average for the class), "+" (more than average for the class), "C" (chlorosis), "N" (necrosis), and X to denote a mesothetic IT with a mixture of ITs on the same leaf.

Molecular marker analysis. Molecular marker analysis was performed on the parents and the RIL population using primer pairs previously designed to both the functional (Rpg5-LRK) and

TABLE 1. Isolates of Puccinia graminis used for phenotypic analysis of the 'Q21861'/'73-G1' recombinant inbred line population

\begin{tabular}{llc}
\hline Pathogen species & Pathotype virulence & Culture accession \\
\hline P. graminis f. sp. tritici & $34-1,2,3,4,5,6,7$ & $74-\mathrm{L}-1$ \\
& $343-1,2(3),(5), 6,9$ & 010047 \\
& $98-1,2,3,5,6,7$ & 033537 \\
P. graminis f. sp. avenae & $41+P g 9, \operatorname{Pg} 13, P g A$ & 962508 \\
& $94+P g 13$ & 923034 \\
P. graminis f. sp. secalis & BWR '2' Rye stem rust & 71327 \\
P. graminis f. sp. secalis $\times$ & Scabrum + Sr21 & 970220 \\
P. graminis f. sp. tritici & & \\
\hline
\end{tabular}

nonfunctional alleles (Rpg5-LRK/PP2C) of the Rpg5 resistance gene, and to the functional Rpgl gene (Rpgl-N) (Table 2) (7). Brueggeman and coauthors (4) previously determined that there was a putative translocation insertion deletion (indel) event, which replaced the serine/threonine protein kinase (S/TPK) domain required for a functional Rpg5 gene with a putative functional protein phosphatase 2C (PP2C). The Rpg5-LRK primers were previously designed to specifically amplify a 1,046-bp fragment of genomic DNA of the functional Rpg5 gene spanning intron 2 (7). The Rpg5-LRK/PP2C primers were designed across the junction between the leucine-rich repeat domain and the PP2C domain and only amplified an 840-bp fragment from genomic DNA when the line contained the PP2C domain, which is a feature of only susceptible lines (7).

Genomic DNA was extracted from 102 RILs and the parental genotypes using the CTAB method essentially as described by Fulton et al. (11). Primer pairs previously designed to Rpgl and both the functional and nonfunctional alleles of Rpg5 (Table 2) were screened essentially as described by Derevnina et al. (7). In brief, polymerase chain reaction (PCR) amplifications were performed in an automated thermocycler (MasterCycler, Eppendorff) using 96 well plates (Astral Scientific). PCR products were amplified from a $10-\mu$ reaction containing $40 \mu \mathrm{M}$ dNTP, $10 \times$ Immolase Buffer (Bioline), $2.5 \mathrm{mM} \mathrm{MgCl}_{2}, 1 \mu \mathrm{M}$ of each primer, $0.2 \mathrm{U}$ of Immolase Taq polymerase (Bioline), and approximately $40 \mathrm{ng}$ of genomic DNA. Thirty-five cycles were conducted in each assay consisting of the following profiles. Annealing temperature and primer sequence information is provided in Table 2. For RPG1-N: denaturation at $94^{\circ} \mathrm{C}$ for $30 \mathrm{~s}$, anneal for $45 \mathrm{~s}$, extension at $72^{\circ} \mathrm{C}$ for $60 \mathrm{~s}$. For Rpg5LRK and Rpg5-LRK/PP2C: denaturation at $94^{\circ} \mathrm{C}$ for $30 \mathrm{~s}$, anneal for $60 \mathrm{~s}$, extension at $72^{\circ} \mathrm{C}$ for $60 \mathrm{~s}$. 'Chevron' and 'Q21861' were used as positive controls for the presence of Rpgl and Rpg5 resistance alleles, respectively.

TABLE 2. Description of markers used to assess the 'Q21861'/'73-G1' F $\mathrm{F}_{8}$ recombinant inbred line population for the presence and absence of the Rpg1 and Rpg5 alleles

\begin{tabular}{llcc}
\hline Marker name & \multicolumn{1}{c}{ Sequence $\left(5^{\prime}-3^{\prime}\right)$} & Size $(\mathrm{bp})$ & Annealing temperature $\left({ }^{\circ} \mathrm{C}\right)$ \\
\hline RPG1-N $^{\mathrm{a}}$ & F:CGGCTAATCACATCAAGTAA & 669 & 61 \\
& R:AGCCCATCATCAATAGACAA & & \\
Rpg5-LRK & F:CTGCTGGCACAGAGTCTGCCTTGAG & 1,046 & 62 \\
& R:ACTCTCGGGTCTGAAGTCCGTGTG & & \\
& F:CTGCTGGCACAGAGTCTGCCTTGAG & 840 & 62 \\
\hline
\end{tabular}

a All primer pairs used for molecular marker analysis were previously published in Derevnina et al. (7).

TABLE 3. Summary of the infection types (ITs) and marker analysis of representative recombinant inbred line (RIL) and parental genotypes of the $\mathrm{F}_{8}$ RIL population of 'Q21861'/'73-G1' inoculated with isolates of Puccinia graminis f. sp. avenae, P. graminis f. sp. tritici, $P$. graminis $\mathrm{f}$. sp. tritici $\times$ P. graminis f. sp. secalis, and P. graminis f. sp. secalis

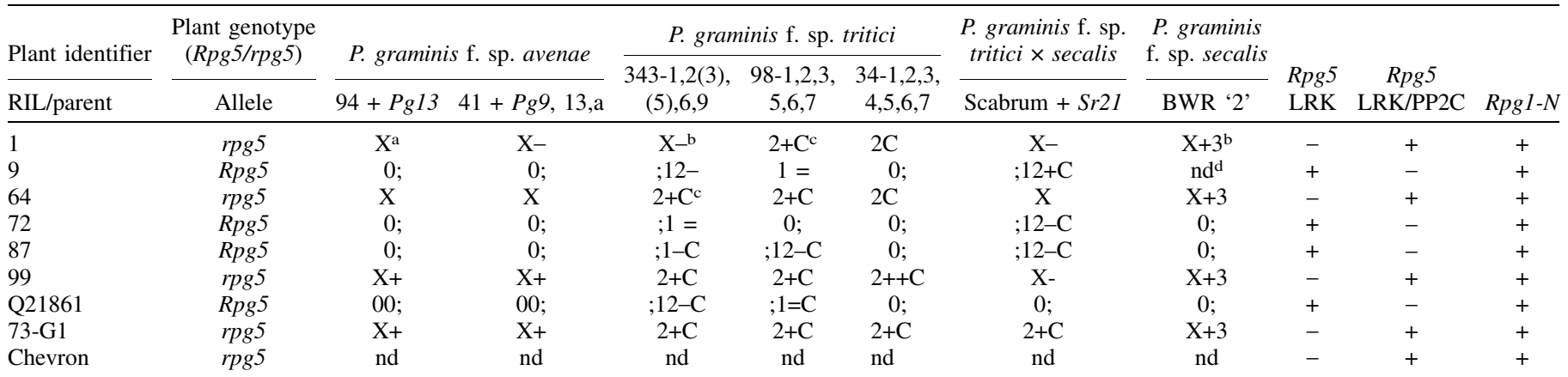

${ }^{a} \mathrm{X}$ denotes a mixed reaction type including pustules of three different sizes $(1,2$, and 3$)$, the - and + following the $\mathrm{X}$ refers to either a higher or lower proportion of pustules with lower IT, respectively.

b $\mathrm{X}+3$ denotes a large proportion of IT 3 pustules compared with others and suggests that the reaction is almost a 3 but also has some mixing of ITs on the same leaf.

c The symbols $\mathrm{C}$ and ; denote the presence of chlorosis and flecking, respectively.

d nd denotes no data. 


\section{RESULTS}

Reaction of barley genotypes to different $\boldsymbol{P}$. graminis cultures. 'Q21861' was resistant to all $P$. graminis cultures tested in this study (Table 3; Fig. 1). ITs were lower (00;) in response to infection by $P$. graminis f. sp. avenae, $P$. graminis $\mathrm{f}$. sp. secalis, 'Scabrum', and P. graminis f. sp. tritici pathotype 34-1,2,3,4,5,6,7 compared with the reactions to $P$. graminis $\mathrm{f}$. sp. tritici pathotypes 343-1,2(3),(5),6,9 (IT ;12-C) and 98-1,2,3,5,6,7 (IT ;1=C) . All resistant RIL progeny had near-immune reactions to $P$. graminis f. sp. avenae, $P$. graminis f. sp. secalis, and pathotype 34$1,2,3,4,5,6,7$, and exhibited low ITs (ranging from 0 ; to ;12C) to pathotypes 343-1,2(3),(5),6,9, 98-1,2,3,5,6,7, and 'Scabrum'. Conversely, the '73-G1' parent and the susceptible RIL lines had higher ITs to both $P$. graminis f. sp. avenae and $P$. graminis f. sp. secalis than to both $P$. graminis f. sp. tritici and 'Scabrum', which gave intermediate ITs. The IT of the 'Q21861' parent was often lower $(0 ;$ to ; $1-\mathrm{C})$ than that seen among resistant RIL progeny $(0$; to $; 12+\mathrm{C}$ ). In all cases, there was no infection of $P$. graminis f. sp. tritici pathotypes on oat variety 'Swan' and no infection of $P$. graminis f. sp. avenae on wheat variety 'Morocco', indicating that there was no cross-contamination of cultures in this experiment (Fig. 1).

Genetic analysis of resistance to the different $P$. graminis cultures in the 'Q21861'/'73-G1' RIL population. The phenotypic assessment of the $\mathrm{F}_{8}$ RIL population derived from intercrossing 'Q21861'/'73-G1' identified two distinct phenotypic classes when assessed by all stem rust fungal cultures (Table 4). From a total of 102 RIL progeny, the segregation of 50 resistant:52 susceptible fitted a 1:1 ratio $\left(X^{2}=0.039, P=0.843\right)$ in tests with all rust isolates, indicative of single gene inheritance pattern (Table 4). Cosegregation patterns of resistant and susceptible lines across three separate pathotypes of $P$. graminis f. sp. tritici, two pathotypes of $P$. graminis f. sp. avenae, and single isolates of $P$. graminis f. $\mathrm{sp}$. secalis and 'Scabrum' indicated that the same or very tightly linked genes are involved in resistance to all rust cultures. Resistance to all P. graminis f. sp. tritici pathotypes cosegregated with resistance to P. graminis f. sp. avenae, $P$. graminis f. sp. secalis, and 'Scabrum' in all cases.

Molecular marker analysis. Molecular analysis was performed on the parental and RIL lines of the 'Q21861'/'73-G1' $F_{8}$ population using previously published perfect markers for both Rpg1 and Rpg 5 (7). Both parents, the positive-Rpgl control 'Chevron', and all RIL progeny were positive for the Rpg1 marker allele, confirming that the 'Q21861'/'73-G1' population was fixed for Rpg1 (Table 3). Further screening with two previously published primer pairs designed to both the functional (Rpg5-LRK) and nonfunctional (Rpg5LRK/PP2C) alleles of the Rpg5 gene demonstrated that ' $Q 21861$ ' was positive for Rpg5-LRK and negative for Rpg5-LRK/PP2C allele. Conversely, 'Chevron' and '73-G1' were positive for the Rpg5-LRK/PP2C allele and negative for Rpg5-LRK, suggesting that both lines do not carry Rpg5. There was cosegregation of RIL lines positive for Rpg5-LRK allele and resistance ITs to all $P$. graminis formae speciales. In all cases, resistant RILs were positive for Rpg5LRK and negative for Rpg5-LRK/PP2C. Conversely, susceptible RILs were negative for Rpg5-LRK and positive for the Rpg5-LRK/

TABLE 4. Joint genotypic and phenotypic segregation analysis of the recombinant inbred line population when tested with three pathotypes of Puccinia graminis f. sp. tritici, two pathotypes of $P$. graminis f. sp. avenae, a single pathotype of $P$. graminis f. sp. secalis and single isolate of $P$. graminis f. sp. tritici $\times P$. graminis $\mathrm{f}$. sp. secalis ('Scabrum' rust)

\begin{tabular}{lccrc}
\hline & \multicolumn{3}{c}{ Number of lines } & \\
\cline { 2 - 4 } Genotype/phenotype & Resistant (R) & Susceptible (S) & Total & $\chi^{2}$ (1R:1S) \\
\hline Rpg5 & 50 & 0 & 50 & No seg. \\
rpg5 & 0 & 52 & 52 & No seg. \\
$\chi^{2}(1$ Rpg5:1 rpg5) & 50 & 52 & 102 & $0.039^{\mathrm{a}}$ \\
\hline
\end{tabular}

${ }^{a} P=0.843(P=3.84$ and 6.64 at $1 \mathrm{df}$ for 5 and $1 \%$, respectively).
PP2C allele (Tables 3 and 4). $\chi^{2}$ analysis found a nearly perfect fit to a 1 Rpg5:1 rpg5 segregation ratio for both marker analysis and phenotypic assessment of resistance and susceptibility (Table 4).

\section{DISCUSSION}

Several genes for resistance in barley to wheat stem rust caused by $P$. graminis f. sp. tritici have been identified and designated, two (Rpg1 and Rpg5) of which have been cloned and characterized $(4,8)$. Previous studies have determined that a single dominant gene in 'Q21861', designated as $R p g Q$, provided high levels of resistance (00;) to $P$. graminis f. sp. secalis (31). This gene was subsequently designated Rpg5 (5), and was recently shown to be required for rpg4-mediated resistance effective to a wide range of $P$. graminis f. sp. tritici pathotypes, including TTKSK $(2,32)$. The present study reports on the genetic analysis of resistance to multiple formae species of $P$. graminis including $P$. graminis $\mathrm{f}$. sp. tritici, $P$. graminis f. sp. secalis, 'Scabrum', and P. graminis f. sp. avenae in an $\mathrm{F}_{8} \mathrm{RIL}$ population derived from an intercross between the $P$. graminis susceptible barley line '73-G1' and 'Q21861'. This population was used in conjunction with molecular markers perfectly linked to both Rpgl and Rpg5 to test the hypothesis that resistance at the Rpg5 locus is effective in response to $P$. graminis f. sp. tritici, $P$. graminis f. sp. secalis, and the heterologous rust pathogen $P$. graminis f. sp. avenae.

$\chi^{2}$ analysis of phenotypic data indicated that the resistant responses to $P$. graminis f. sp. tritici, $P$. graminis f. sp. secalis, 'Scabrum', and P. graminis f. sp. avenae observed in the 'Q21861'/ '73-G1' RIL population was monogenically inherited. Cosegregation of phenotypic data with molecular marker analysis of the RIL progeny found that resistance always cosegregated with the presence of the Rpg5 marker allele, implying that resistance to $P$. graminis f. sp. avenae was associated with Rpg5. Martens and coworkers (20) previously performed allelism tests on two barley cultivars that were resistant to $P$. graminis f. sp. avenae and no segregation was observed, suggesting the presence of the same gene for resistance to $P$. graminis f. sp. avenae in both genotypes, which differed from the resistance gene effective against $P$. graminis $\mathrm{f}$. sp. tritici. Phenotypic assessment of the parental genotypes of the 'Q21861'/'73-G1' RIL population in the present study determined that the 'Q21861' parent was highly resistant to all isolates of P. graminis tested. Conversely, '73-G1' was moderately susceptible to Australian P. graminis f. sp. avenae pathotypes but showed an intermediate level of resistance to the Australian P. graminis f. sp. tritici pathotypes used in this study. Martens et al. (20) originally determined that ' $73-\mathrm{G} 1$ ' was moderately susceptible to Canadian pathotypes of $P$. graminis $\mathrm{f}$. sp. avenae and resistant to a Canadian pathotype of $P$. graminis f. sp. tritici. Previous studies on resistance to different formae speciales of $P$. graminis in barley have never reported on full susceptibility in barley to $P$. graminis f. sp. tritici or $P$. graminis f. sp. avenae but rather mesothetic reactions with a mixture of ITs consistent with moderate susceptibility $(7,9,20)$. Molecular marker analysis in this study determined that both parents and all RIL progeny were positive for the presence of Rpg1, indicating the gene was fixed in this population. Despite this, there was no clear indication of incompatibility associated with Rpgl to any of the Australian $P$. graminis cultures used in this study. Derevnina and coworkers (7) previously reported the inability to detect Rpgl with Australian P. graminis f. sp. tritici pathotypes, including $98-1,2,3,5,6,7$ that was used in the current study (7). It is however possible that the observed resistance in '73-G1' is an uncharacterized resistance gene effective against Australian P. graminis f. sp. tritici isolates.

Previous studies suggest that genetic resistance in barley to heterologous rust pathogens is highly diverse and largely dependent on plant genotype $(9,13)$. The literature reports on a large reservoir of genes for nonhost resistance that often overlap with partial resistance mechanisms to adapted pathogens. A recent study 
identified four to five quantitative trait locus (QTL) for prehaustorial resistance to Canadian and Australian pathotypes of P. graminis f. sp. avenae in a barley doubled haploid population (9). Similar findings were also observed in response to numerous heterologous rusts in three separate mapping populations, where each of the resistant parents contributed different QTL for resistance (13). In the present study, a single gene, either Rpg5 or a gene very closely linked to Rpg5 and showing a similar incompatible phenotype, was effective against two Australian pathotypes of $P$. graminis f. sp. avenae, however genetic analysis with a larger population size may aid in the further identification of additional minor resistance QTL.

Although all resistant lines were found to carry the Rpg5-LRK marker, and all susceptible lines carried the Rpg5-LRK/PP2C marker, it is unknown it the resistance to $P$. graminis f. sp. avenae is due to Rpg5 or to one or more closely linked genes at the Rpg5 locus. In an RIL population size of 102 lines, the estimated linkage distance is 5 to $6 \mathrm{cM}$, thus a larger population size is needed to determine conclusively if the resistance to $P$. graminis f. sp. avenae (and other formae speciales) is due to Rpg5. The Rpg5 locus is complex, with at least four genes at two loci (RMRL1 and RMRL2) needed to confer high level of rpg4 resistance to P. graminis f. sp. tritici pathotypes QCCJ and TTKSK (32). Further research using high resolution analyses and gene silencing found that of three tightly linked genes (HvAdf3, HvRgal, Rpg5), the Rpg5 gene was needed to confer rpg4 and Rpg5 resistance to $P$. graminis f. sp. tritici and $P$. graminis f. sp. secalis (2). Similar research is needed to elucidate the gene conferring resistance to 'Scabrum' and $P$. graminis f. sp. avenae, but it appears that this gene is near the Rpg5 locus and may in fact be the Rpg5 gene that confers resistance to $P$. graminis f. sp. tritici and $P$. graminis f. sp. secalis.

In summary, we have determined that a single gene at or near the Rpg5 locus (contributed by 'Q21861') is effective against multiple Australian pathotypes of $P$. graminis f. sp. tritici, $P$. graminis f. sp. secalis, and 'Scabrum' as well as the heterologous rust $P$. graminis f. sp. avenae. Analysis using diagnostic markers for both resistant and susceptible alleles of the Rpg 5 gene found that only resistant lines were positive for the marker, but further testing with a larger population size is needed to perform fine-mapping and confirm if it is indeed Rpg 5 that confers resistance to $P$. graminis f. sp. avenae. Additional testing with other formae speciales of $P$. graminis including f. spp. lolii and dactylis is planned to determine the role of Rpg5 in these pathosystems and whether Rpg5 is involved in PAMP-triggered immunity in barley.

\section{ACKNOWLEDGMENTS}

This research was supported by the Australian Research Council. We thank M. Williams and G. Standon for valuable technical support.

\section{LITERATURE CITED}

1. Anikster, Y. 1984. The formae speciales. Pages 115-130 in: The Cereal Rusts. Vol. 1. W. R. Bushnell and A. P. Roelfs, eds. Academic Press, NY.

2. Arora, D., Gross, T., and Brueggeman, R. 2013. Allele characterization of genes required for rpg4-mediated wheat stem rust resistance identifies Rpg5 as the $R$ gene. Phytopathology 103:1153-1161.

3. Atienza, S., Jafary, H., and Niks, R. 2004. Accumulation of genes for susceptibility to rust fungi for which barley is nearly a nonhost results in two barley lines with extreme multiple susceptibility. Planta 220:71-79.

4. Brueggeman, R., Druka, A., Nirmala, J., Cavileer, T., Drader, T., Rostoks, N., Mirlohi, A., Bennypaul, H., Gill, U., Kudrna, D., Whitelaw, C., Kilian, A., Han, F., Sun, Y., Gill, K., Steffenson, B., and Kleinhofs, A. 2008. The stem rust resistance gene Rpg5 encodes a protein with nucleotide-binding-site, leucine-rich and protein kinase domains. Proc. Natl. Acad. Sci. USA 105:14970-14975.

5. Brueggeman, R., Rostoks, N., Kudrna, D., Kilian, A., Han, F., Chen, J., Druka, A., Steffenson, B., and Kleinhofs, A. 2002. The barley stem rustresistance gene Rpgl is a novel disease-resistance gene with homology to receptor kinases. Proc. Natl. Acad. Sci. USA 99:9328-9333.

6. Brueggeman, R., Steffenson, B. J., and Kleinhofs, A. 2009. The rpg4/ Rpg5 stem rust resistance locus in barley: Resistance genes and cytoskeleton dynamics. Cell Cycle 8:977-981.
7. Derevnina, L., Fetch, T., Singh, D., Brueggeman, R., Dong, C., and Park, R. F. 2014. Analysis of stem rust resistance in Australian barley cultivars. Plant Dis. 98:1485-1493.

8. Dill-Macky, R., Ress, R. G., and Platz, G. J. 1990. Stem rust epidemics and their effects on grain yield and quality in Australian barley cultivars. Aust. J. Agric. Res. 41:1057-1063.

9. Dracatos, P., Ayliffe, M., Khatkar, M., Fetch, T., Singh, D., and Park, R. 2014. Inheritance of pre-haustorial resistance to Puccinia graminis f. sp. avenae in barley (Hordeum vulgare L.). Mol. Plant-Microbe Interact. 27:1253-1262.

10. Fetch, T., Johnston, P. A., and Pickering, R. 2009. Chromosomal location and inheritance of stem rust resistance transferred from Hordeum bulbosum into cultivated barley (H. vulgare). Phytopathology 99:339-343.

11. Fulton, T., Chunwongse, J., and Tanksley, D. 1995. Microprep protocol for extraction of DNA from tomato and other herbaceous plants. Plant Mol. Biol. Rep. 13:207-209.

12. Green, G. 1971. Hybridization between Puccinia graminis tritici and Puccinia graminis secalis and its evolutionary implications. Can. J. Bot. 49:2089-2095

13. Jafary, H., Albertazzi, G., Marcel, C., and Niks, R. 2008. High diversity of genes for non-host resistance of barley to heterologous rust fungi. Genetics 178:2327-2339.

14. Jedel, P. E. 1990. A gene for resistance to Puccinia graminis f. sp. tritici in PI 382313. Barley Genet. Newsl. 20:43-44.

15. Jedel, P. E., Metcalfe, D. R., and Martens, J. W. 1989. Assessment of barley accessions PI 382313, PI 382474 and PI 382976 for stem rust resistance. Crop Sci. 29:1473-1477.

16. Jin, Y., Steffenson, B. J., and Miller, J. D. 1994. Inheritance of resistance to pathotypes QCC and MCC of Puccinia graminis f. sp. tritici in barley line Q21861 and temperature effects on the expression of resistance. Phytopathology 84:452-455.

17. Johnson, T. 1949. Intervarietal crosses in Puccinia graminis. Can. J. Res. Sect. C 27:45-65.

18. Kleinhofs, A., Brueggeman, R., Nirmala, J., Zhang, L., Mirlohi, A., Druka, A., Rostoks, N., and Steffenson, B. 2010. Barley stem rust resistance genes: Structure and function. Plant Genome 2:109-112.

19. Luig, N. H., and Watson, I. A. 1972. The role of wild and cultivated grasses in the hybridization of formae speciales of Puccinia graminis. Aust. J. Biol. Sci. 25:335-342.

20. Martens, J., Green, G., and Buchannon, K. 1983. Inheritance of resistance to Puccinia graminis f. sp. avenae in a Hordeum vulgare selection. Can. J. Plant Pathol. 5:266-268.

21. Miller, J. D., and Lambert, J. W. 1955. Variability and inheritance of reaction of barley to race 15B of stem rust. Agron. J. 47:373-377.

22. Park, R. F. 2007. Stem rust of wheat in Australia. Aust. J. Agric. Res. 58:558-566.

23. Patterson, F. L., Shands, R. G., and Dickson, J. G. 1957. Temperature and seasonal effects on seedling reactions of barley varieties to three races of Puccinia graminis f. sp. tritici. Phytopathology 47:395-402.

24. Shands, R. G. 1939. Chevron, a barley variety resistant to stem rust and other diseases. Phytopathology 29:209-211.

25. Singh, R. P., Hodson, D. P., Huerta-Espino, J., Jin, Y., Njau, P., Wanyera, R., Herrera-Foessel, S. A., and Ward, R. W. 2008. Will stem rust destroy the world's wheat crop? Adv. Agron. 98:271-309.

26. Stakman, E. C., Stewart, D. M., and Loegering, W. Q. 1962. Identification of physiological races of Puccinia graminis var. tritici. Agricultural Research Service E617. United States Department of Agriculture, Washington, DC

27. Steffenson, B. J. 1992. Analysis of durable resistance to stem rust in barley. Euphytica 63:153-167.

28. Steffenson, B. J., Jin, Y., Brueggeman, R. S., Kleinhofs, A., and Sun, Y. 2009. Resistance to stem rust race TTKSK maps to the rpg4/Rpg5 complex of chromosome 5H of barley. Phytopathology 99:1135-1141.

29. Steffenson, B. J., Miller, J. D., and Jin, Y. 1993. Detection of the stem rust resistance gene Rpg1 in barley seedlings. Plant Dis. 77:626-629.

30. Sun, Y., and Steffenson, B. J. 2005. Reaction of barley seedlings with different stem rust resistance genes to Puccinia graminis f. sp. tritici and Puccinia graminis f. sp. secalis. Can. J. Plant Pathol. 27:80-89.

31. Sun, Y., Steffenson, B. J., and Jin, Y. 1996. Genetics of resistance to Puccinia graminis f. sp. secalis in barley line Q21861. Phytopathology 86: 1299-1302.

32. Wang, X., Richards, J., Gross, T., Druka, A., Kleinhofs, A., Steffenson, B., Acevedo, M., and Brueggeman, R. 2013. The rpg4-mediated resistance to wheat stem rust (Puccinia graminis) in barley (Hordeum vulgare) requires Rpg5, a serine NBS-LRR gene, and an actin depolymerization factor. Mol. Plant-Microbe Interact. 26:407-418.

33. Wanyera, R., Kinyua, M. G., Jin, Y., and Singh, R. P. 2006. The spread of stem rust caused by Puccinia graminis f. sp. tritici, with virulence on $\mathrm{Sr} 31$ in wheat in Eastern Africa. Plant Dis. 90:113.

34. Zambino, P. J., and Szabo, L. J. 1993. Phylogenetic relationships of selected cereal and grass rusts based on rDNA sequence analysis. Mycologia 85:401-414 